\title{
Effects of caffeic acid and bovine serum albumin in reducing the rate of development of rancidity in oil-in-water and water-in-oil emulsions
}

Article

Accepted Version

Conde, E., Gordon, M. H., Moure, A. and Dominguez, H.

(2011) Effects of caffeic acid and bovine serum albumin in reducing the rate of development of rancidity in oil-in-water and water-in-oil emulsions. Food Chemistry, 129 (4). pp. 16521659. ISSN 0308-8146 doi:

https://doi.org/10.1016/j.foodchem.2011.06.027 Available at https://centaur.reading.ac.uk/22824/

It is advisable to refer to the publisher's version if you intend to cite from the work. See Guidance on citing.

To link to this article DOI: http://dx.doi.org/10.1016/j.foodchem.2011.06.027

Publisher: Elsevier

All outputs in CentAUR are protected by Intellectual Property Rights law, including copyright law. Copyright and IPR is retained by the creators or other copyright holders. Terms and conditions for use of this material are defined in the End User Agreement. 


\section{www.reading.ac.uk/centaur}

\section{CentAUR}

Central Archive at the University of Reading

Reading's research outputs online 

Development of Rancidity in Oil-in-water and Water-in-oil Emulsions

3 ENMA CONDE ${ }^{1}$, MICHAEL H.GORDON ${ }^{2}$, ANDRÉS MOURE $^{1}$ and HERMINIA DOMINGUEZ ${ }^{1}$

$5 \quad{ }^{1}$ Departamento de Enxeñería Química, Universidade de Vigo (Campus Ourense), Edificio Politécnico As Lagoas s/n, 32004, Ourense, Spain

$7{ }^{2}$ Hugh Sinclair Unit of Human Nutrition, Department of Food and Nutritional Sciences, The 8 University of Reading, Whiteknights P.O. Box 226, Reading RG6 6AP, United Kingdom

11 AUTHOR EMAIL ADDRESS m.h.gordon@ reading.ac.uk

12

13 RECEIVED DATE

14 TITLE RUNNING HEAD Effects of caffeic acid and bovine serum albumin on rancidity 15 development in emulsions

16 CORRESPONDING AUTHOR FOOTNOTE Phone +44 1183786723 Fax: +44 1189310080

17

18

19

20 


\section{ABSTRACT}

26 The antioxidant properties of caffeic acid and bovine serum albumin in oil-in-water and water-in-oil

27 emulsions were studied. Caffeic acid ( $5 \mathrm{mmol} / \mathrm{kg}$ emulsion) showed good antioxidant properties in 28 both $30 \%$ sunflower oil-in-water (OW) and $20 \%$ water-in-sunflower oil emulsions (WO), pH 5.4, 29 during storage at $50{ }^{\circ} \mathrm{C}$. Although bovine serum albumin (BSA) $(0.2 \%)$ had a slight antioxidant effect, 30 the combination of caffeic acid and BSA showed a synergistic reduction in the rate of development of 31 rancidity, with significant reductions in concentration of total volatiles, peroxide value (PV) and p32 anisidine value (PA) for both emulsion types. The synergistic increase in stability of the OW and WO 33 emulsions containing BSA and caffeic acid was 102.9 and $50.4 \%$ respectively based on TOTOX 34 values, which are calculated as $2 \mathrm{PV}+\mathrm{PA}$, with greater synergy calculated if based on formation of 35 headspace volatiles, The OW emulsion was more susceptible to the development of headspace 36 volatiles by oxidation than the WO emulsion, even though the degree of oxidation assessed by the 37 TOTOX value was similar. 


\section{INTRODUCTION}

Lipid oxidation is of great concern to the consumer because it causes not only changes in the quality

51 attributes of foods, including taste, texture, shelf life, appearance and flavor, but also due to the strong

52 decrease in the nutritional value and safety caused by the loss of antioxidants and the formation of 53 harmful components including free radicals and reactive aldehydes (Halliwell, Murcia, Chirico \& 54 Aruoma, 1995).

55 Oxidation in food emulsions is of particular interest since oil is widely consumed in foods which are 56 either water-in-oil, for example, butter and margarine, or oil-in-water emulsions, for example, 57 mayonnaise, milk and cream. Lipid oxidation in emulsions is generally recognized as being more 58 complex than lipid oxidation in bulk oil systems, as the emulsification process will lead to the 59 formation of a large interfacial area, and lipid oxidation is initiated at the interface between oil and 60 water, where different non-polar and polar compounds in the system can interact (Frankel, 1998; $61 \quad$ McClements \& Decker, 2000).

62 One of the most effective methods of retarding lipid oxidation in fatty foods is to incorporate 63 antioxidants. The behavior of antioxidants is also more complex in emulsions than in bulk oil since 64 more variables are involved, including the emulsifier and pH (Mancuso, McClements \& Decker, 1999; 65 SØrensen et al., 2008). Antioxidant efficacy in food systems depends on various factors including the 66 structure (i.e., number and position of hydroxyl groups bound to the aromatic ring and presence of 67 other substituents), chemical reactivity of the phenolics, interactions with food components, and 68 environmental conditions. The partitioning of the antioxidant into the different phases is an important 69 factor for emulsions (Decker, Warner, Richards \& Shahidi, 2005). The efficacy of antioxidants in bulk 70 oil and in dispersed systems is affected by their polarity as described by the "polar paradox" (Frankel, 71 Huang, Kanner \& German, 1994). According to the polar paradox, polar antioxidants like ascorbic 
acid and Trolox are more active in non-polar media like bulk oils than less polar components including ascorbyl palmitate and tocopherol. These apparent paradoxical effects of the antioxidants have been reported as being due to the polar antioxidants being located at the air-oil interface in bulk oils, i.e. situated where oxidation is suggested to take place or at least to be initiated. In addition, they may act in non-polar media by chelation of metal ions. On the other hand, lipophilic antioxidants are more active in polar systems, because they are located at the oil-water interface where oxidation is propagated (Frankel et al, 1994; Huang, Hopia, Schwarz, Frankel \& German, 1996; Porter, 1993).

Phenolic compounds, such as caffeic acid, have received increasing interest due to their antioxidant activity, which improves the stability of lipid-containing foods and their possible beneficial effects on

81 human health. Caffeic acid may exert its antioxidant effect by donating a hydrogen atom to free radicals, thereby acting as chain-breaking antioxidants, or may act as a metal chelator, which reduces the activity of prooxidants (Gülçin, 2006; Leonardis \& Macciola, 2003).

Although antioxidants have been frequently studied in oils, emulsions, and other foods, there have been few reports of how proteins, which are commonly present in foods, may affect the activity of antioxidants. Most antioxidants of interest for foods have one or more phenolic hydroxyl groups, and several studies have demonstrated that molecules with this structure may bind to proteins. Polyphenols may associate with proteins through hydrophobic interactions and hydrogen bonding (Oda, Kinoshita, Nakayama \& Kakehi, 1998), and a range of phenolic antioxidants has also been shown to bind to bovine skin proteins (Wang \& Goodman, 1999).

91 Proteins have been shown to have weak antioxidant activity including both metal chelating and radical 92 scavenging activity (Arcan \& Yemenicioğlu. 2007). Bovine serum albumin (BSA), a minor whey 93 protein with M.W. $66 \mathrm{kDa}$ has surface-active properties and has been used to stabilize model food 94 emulsions (Rampon, Lethuaut, Mouhous-Riou \& Genot, 2001). 
The aim of this study was to determine the influence of BSA on the total antioxidant activity of caffeic acid in model food emulsions. The $\mathrm{pH}$ of the emulsions was 5.4 , which is a typical $\mathrm{pH}$ for margarine samples.

\section{MATERIALS AND METHODS}

\subsection{Chemicals}

All solvents used were analytical or HPLC grade (Merck \& Co. Inc., Darmstadt, Germany). Isooctane, glacial acetic acid, ferrous sulfate, barium chloride, ammonium thiocyanate, polyoxyethylene sorbitan monolaurate (Tween-20), p-anisidine, cumene hydroperoxide, bovine serum albumin (BSA), hexanal, and bromobenzene were purchased from Sigma-Aldrich (Gillingham, Dorset, UK). Refined sunflower oil was purchased from a local retail outlet. Fatty acids were purchased from Sigma Chemical Co. (Saint Louis, MO, USA).

The fatty acid composition of the sunflower oil is shown in Table 1.

\subsection{Removal of tocopherols from sunflower oil}

Tocopherols were removed from sunflower oil by column chromatography using activated alumina as described by Yoshida, 1993.

\subsection{Emulsion preparation}

Oil-in-water emulsions (30\% oil) were prepared by dissolving Tween-20 (1\%) in acetate buffer $(0.1$ $\mathrm{M}, \mathrm{pH}$ 5.4), either with or without BSA (0.2\%) and caffeic acid (5 mmol/kg emulsion). Water-in-oil emulsions $\left(20 \%\right.$ water) were prepared by dissolving Dimodan ${ }^{\circledR}(1 \%)$ in acetate buffer $(0.1 \mathrm{M}, \mathrm{pH}$ 5.4), either with or without BSA $(0.2 \%)$ and caffeic acid $(5 \mathrm{mmol} / \mathrm{kg}$ emulsion). Emulsions were prepared by the dropwise addition of oil to the water phase, with sonication by a Vibracell sonicator

17 (Sonic \& Materials, Newton, CT, USA) whilst cooling in an ice bath for $5 \mathrm{~min}$.

\subsection{Emulsion oxidation}


119 All emulsions were stored in triplicate in $25 \mathrm{~mL}$ glass bottles in the dark (inside an oven) at $50^{\circ} \mathrm{C}$, and 120 each replicate was analysed once.

121 Aliquots of each emulsion were removed periodically for peroxide value (PV), $p$-anisidine value (PA) 122 determinations and for analysis of volatile oxidation products by gas chromatography (GC)

\subsection{Determination of fatty acid composition}

124 The fatty acid composition of sunflower oil was determined by GC on an HP Agilent 6890N 125 chromatograph equipped with a HP 7683 injector and a flame ionization detector (FID). Fatty acid 126 methyl esters (FAMEs) were prepared by transesterification according to Shehata, de Man \& 127 Alexander, 1970. Chromatographic separation was carried out using a SP-2560 column (100 m length, $1280.25 \mathrm{~mm}$ ID and $0.20 \mu \mathrm{m}$ film thickness; Supelco). The oven temperature was $120{ }^{\circ} \mathrm{C}$ for $5 \mathrm{~min}$, 129 followed by temperature programming to $170{ }^{\circ} \mathrm{C}$ at $2{ }^{\circ} \mathrm{C} \min ^{-1}, 200{ }^{\circ} \mathrm{C}$ at $5{ }^{\circ} \mathrm{C} \min ^{-1}$, and then 130 increased to $235^{\circ} \mathrm{C}$ at $2{ }^{\circ} \mathrm{C} \mathrm{min}{ }^{-1}$. Helium was used as carrier gas, the FID temperature was $280{ }^{\circ} \mathrm{C}$ and 131 the injection port was held at $260^{\circ} \mathrm{C}$.

\subsection{Spectrophotometric determination of peroxide value (PV)}

133 Emulsion $(0.3 \mathrm{~mL})$ was added to isooctane/2-propanol $(3: 2 \mathrm{v} / \mathrm{v}, 1.5 \mathrm{~mL})$ and the mixture was mixed 134 on a vortex mixer three times for $10 \mathrm{~s}$ each time. After centrifugation for $2 \mathrm{~min}$ at $1000 \mathrm{xg}$, the clear 135 upper layer $(0.2 \mathrm{~mL})$ was collected and peroxides were quantified using a method based on that of 136 Díaz, Dunn, McClements \& Decker, 2003. Lipid peroxide concentration was determined using a 137 cumene hydroperoxide standard curve $\left(r^{2}=0.9977\right)$.

\subsection{Spectrophotometric determination of p-anisidine Value (PA)}

139 The PA value was determined by AOCS Official Method no. cd 18-90, 1989.

\subsection{Solid phase microextraction (SPME) sampling conditions}

141 An aliquot of emulsion $(0.2 \mathrm{~g})$ was weighed in a $2 \mathrm{~mL}$ vial. A magnetic follower was added and the

142 vial was capped with a Teflon-faced rubber septum and plastic cap. The vial was placed in a water 143 bath on a magnetic stirrer and the sample was equilibrated for $2 \mathrm{~min}$ at $60^{\circ} \mathrm{C}$. The septum was 
144 manually pierced with the SPME needle and the fiber was exposed to the emulsion headspace for 60

145 min and transferred to the gas chromatograph where the volatiles were desorbed in the injection port.

146 The desorption time in the injection port was $15 \mathrm{~min}$.

147 2.9. SPME/GC analysis

148 Volatile oxidation compounds were monitored by headspace analysis with solid phase microextraction 149 (HS-SPME). A manual SPME fiber holder unit and $30 \mu \mathrm{m}$ DVB-CAR-PDMS fiber (Sigma-Aldrich 150 Company Ltd., Dorset, UK) were used to adsorb volatiles from the emulsion in a closed vial at $60^{\circ} \mathrm{C}$ 151 with a sampling time of $60 \mathrm{~min}$. GC analyses were performed with a HP 5890 series II gas 152 chromatograph (Agilent UK, South Queensferry, UK) equipped with FID detector and split/splitless 153 injector. Chromatographic separation was carried out using a HP-5-column (15 m length, $0.25 \mathrm{~mm}$ ID 154 and $0.25 \mu \mathrm{m}$ film thickness; Agilent UK). The oven temperature was $40{ }^{\circ} \mathrm{C}$ for $10 \mathrm{~min}$, followed by 155 temperature programming to $140{ }^{\circ} \mathrm{C}$ at $2.5{ }^{\circ} \mathrm{C} \mathrm{min}{ }^{-1}$, and then increased to $300{ }^{\circ} \mathrm{C}$ at $20{ }^{\circ} \mathrm{C} \min ^{-1}$. 156 Helium was used as carrier gas in the splitless mode. The FID temperature was $280{ }^{\circ} \mathrm{C}$ and the 157 injection port was held at $260^{\circ} \mathrm{C}$.

158 The identification of all compounds was based on the mass spectra determined by GC-MS using a HP 1595890 series II gas chromatograph with MS detector and by comparison of their retention time with 160 those of authentic standards. Retention times for a series of n-alkanes $\left(\mathrm{C}_{5}-\mathrm{C}_{25}\right)$ were determined and 161 used to calculate the Linear Retention Indices (LRI values) of detected compounds.

162 Bromobenzene $(1 \mu \mathrm{L} / \mathrm{g}$ emulsion) was added as an internal standard prior to analysis. The relative 163 concentrations of the investigated compounds were calculated by relating the area of the internal 164 standard to the area of the compound of interest, defined as:

165 Relative conc. $=\frac{\text { Peak area of particular compound }}{-}-\mathrm{x}$ IS conc. 
167 Confocal microscopy was performed with a Leica TCS SP2 AOBS confocal laser scanning 168 microscope mounted on a Leica inverted DM IRE2 microscope for the oil-in-water emulsions and 169 with a Leica TCS SP5 confocal laser microscope for the water-in-oil emulsions.. A Nile Red/Nile Blue 170 mixture $(0.01 \%)$ was added to an emulsion sample and examined using x10, x20 and x 40 objectives. 171 The image was obtained by exciting the sample with a 633nm Helium-Neon laser with an emission 172 band of 630-750nm.

\subsection{Calculation of synergy}

175 Synergy was calculated by comparing the times to a given level of deterioration, defined as induction 176 period for the calculation, as described in Almajano \& Gordon, 2004.

$$
\% \text { synergism }=100 \frac{[\mathrm{P}(a+p)-\operatorname{IP}(c)\rfloor[\mathrm{IP} a-\operatorname{IP} c)+(\operatorname{IP} p-\operatorname{IP} c)^{-}}{[\operatorname{IP} a-\operatorname{IP} c)+(\operatorname{IP} p-\operatorname{IP} c)]}
$$

178 where $\mathrm{IP}=$ induction period, $a=$ antioxidant, $p=$ protein and $c=$ control.

\subsection{Statistical analysis}

180 The triplicate determinations were used to calculate the mean (m), standard deviation (sd), and 181 standard error of the mean (SEM).

182 Times to selected levels of deterioration were compared, and significant differences at the $5 \%$ level 183 were assessed by one-way ANOVA using commercial software (Statistica 6.0). To verify the 184 association among experimental data, Pearson correlation analysis was performed using the same 185 statistical package; $\mathrm{p}$-values $<0.05$ were considered significant.

\section{RESULTS AND DISCUSSION}


189 The sunflower oil used contained linoleic acid $(64.17 \%)$, and oleic acid $(25.01 \%)$ as the main 190 unsaturated fatty acids, with linolenic acid being present at $0.16 \%$ (Table 1).

191 The emulsions were stored at $50{ }^{\circ} \mathrm{C}$ to accelerate oxidative changes that would occur more slowly, at 192 lower temperatures. Reproducibility of the data was good with the SEM being <25\% for $80 \%$ of the 193 samples analysed by PV, and the SEM being <25\% for $90 \%$ of the samples analysed by PA.

194 The initial PV of the emulsion samples was similar with values of $0.05 \mathrm{mM}$ cumene hydroperoxide for 195 OW emulsions and 0.07-0.17 mM for WO emulsions. After 14 days of oxidation the OW emulsions 196 reached significantly different PV values in the order: OW > OW-BSA > OW-CAF > OW-CAF-BSA. 197 The PV values reached in WO emulsions were in the same order up to 35 days but the PV of WO198 CAF was higher than WO-BSA at 42 days, since the PV of the control and BSA samples declined 199 sharply after 35 days with corresponding sharp increases in PA values indicating degradation of the 200 hydroperoxides.

201 As shown in Figure 1, the maximum PV reached was $10.43 \mathrm{mM}$ hydroperoxide at 42 days for the OW 202 sample, followed by $7.72 \mathrm{mM}$ hydroperoxide for OW-BSA. In WO emulsions the maximum value 203 was reached at 35 days for the WO sample followed by the WO-BSA sample (6.28 and $5.44 \mathrm{mM}$ 204 hydroperoxide, respectively); then there was a decrease in PV for all WO emulsions as the rate of 205 hydroperoxide formation became less than hydroperoxide decomposition.

206 At 35 days of storage, the extent of formation of hydroperoxides in the OW-CAF and WO-CAF 207 samples was lower than in the appropriate control sample with inhibition of 66.7 and $34.7 \%$, 208 respectively, indicating the antioxidant effect of caffeic acid. The greater effect in the OW emulsion 209 may be due to type of emulsion, the higher caffeic acid:oil ratio $(16.7 \mathrm{mmol} / \mathrm{kg}$ oil $)$ in the OW 210 emulsion, which was 2.7 times higher than in the WO emulsion $(6.25 \mathrm{mmol} / \mathrm{kg}$ oil $)$ and the difference 211 between oil concentration in the emulsions. BSA increased the activity of caffeic acid in both 212 emulsions. 
214 The PA value determination, a measure of secondary oxidation products (List, Evans, Kwolek, 215 Warner, Boundy \& Cowan, 1974), confirmed the findings of the PV analysis. The PA test was used to 216 determine the level of aldehydes, principally 2-alkenals and 2,4-alkadienals, present in the emulsions. 217 The PA values were relatively stable for the samples with caffeic acid, and with both caffeic acid and 218 BSA throughout the study.

219 As shown in Table 2, in the presence of BSA, the stability of the OW emulsions containing caffeic 220 acid increased by more than $200 \%$, when assessed by the time to PA $=0.15$, but BSA did not 221 contribute any significant increase in stability to WO emulsions containing caffeic acid when assessed 222 by the PA values. The TOTOX value is a measure of both primary and secondary oxidation products, 223 where TOTOX = 2PV + PA. Synergy between the caffeic acid and bovine serum albumin, in retarding 224 oxidation of emulsions, was investigated by consideration of the TOTOX values. As shown in Table 2252 , the OW sample took 8.19 days to reach a TOTOX value of 3.7, followed by OW-BSA with 10.72 226 days, then OW-CAF with 23.7 days and finally OW-CAF-BSA, the most stable, with 42 days. The 227 WO emulsions showed similar times to reach a TOTOX value of 8.9.

229 Headspace solid phase microextraction (HS-SPME) was used to isolate the headspace volatile 230 products formed during secondary oxidation of OW and WO emulsions. Volatile aldehydes have great 231 importance as oxidation products because of their contribution to the aroma of oxidised oils and 232 emulsions. Hydrophobic flavor components can be perceived at lower concentrations in water than in 233 oil, since many of the lipid oxidation products have higher solubility in the oil phase. This means that, 234 for a fixed concentration of volatile components, their concentration in the headspace of an emulsion 235 decreases as the oil concentration increases. As a consequence, a low fat emulsion may be perceived 236 as more oxidized than a high fat emulsion, even though both emulsions have the same concentration of 237 volatile components. 
238 Figure 2 shows the change in concentration of hexanal and total volatile products with time expressed 239 as relative peak area. Hexanal has been widely used as a marker of volatile oxidation products of n-6 240 fatty acids in previous studies (Rouseff \& Cadwallader, 2001). In both systems, hexanal was the main 241 volatile formed during storage. The OW emulsion was more susceptible to headspace volatile 242 formation than the WO emulsion, as shown by the considerably higher concentrations of total volatiles 243 that were formed, even though the degree of oxidation assessed by the TOTOX value was not 244 significantly different in the two emulsion types (Table 3). At day 42, the TOTOX value for the OW 245 emulsion containing caffeic acid and BSA was even lower than that of the analogous WO emulsion. 246 The difference in headspace volatile concentration is partly due to the reduction of vapour pressure of 247 each volatile component in the greater mass of oil present in the WO emulsions, since, according to 248 Raoult's law, the vapour pressure of a solute is proportional to its molar concentration. However, 249 differences in the relative importance of hydroperoxide decomposition pathways into volatile and non250 volatile products may also occur in the different emulsion types, since the headspace volatile: PA ratio 251 after 42 days storage was 6.7-7.9 times higher in the OW emulsion than in the corresponding WO 252 emulsion, for samples containing no additive, BSA or caffeic acid and 49.3 times higher for the 253 samples containing caffeic acid and BSA (Table 3). The higher oxidative susceptibility of OW 254 emulsions has been reported extensively, and it is attributed to the greater extent of interfacial 255 interactions that are possible between the lipid substrate and prooxidants including metal ions in the 256 aqueous phase as a consequence of the greater surface area presented by the emulsion droplets 257 (McClements \& Decker, 2000; Jacobsen, Let, Nielsen \& Meyer, 2008). It has been suggested that lipid 258 oxidation in WO emulsions will occur at a rate similar to that in bulk oils because the surface of the 259 lipid phase is exposed directly to air (McClements \& Decker, 2000), but effects of antioxidants, metal 260 ions and chelating agents will differ in these media. In WO emulsions, caffeic acid inhibited the 261 formation of hexanal and total volatile compounds at the end of the storage period by 75.48 and 53.51 $262 \%$, respectively. Caffeic acid showed good antioxidant properties in OW emulsions inhibiting the 263 formation of hexanal and total volatile compounds by 95.08 and $87.27 \%$, respectively. BSA increased 
the antioxidant activity of caffeic acid in inhibiting the formation of hexanal and volatile compounds in the later stages of storage in WO emulsions (by 18.49 and $26.49 \%$, respectively), but was less effective in OW emulsions (2.51 and $3.32 \%$, respectively).

267 The synergistic increase in stability of the OW and WO emulsions prepared with BSA containing 268 caffeic acid was 277.34 and $468.53 \%$, respectively, based on the time for the total volatile 269 concentration to reach 585.37 and $364.56 \mu \mathrm{g}$ bromobenzene/ g oil, respectively (Table 2).

270 Positive correlations between PV and total volatiles ( $\mathrm{r}=0.892)$ and also between PA and both hexanal 271 and total volatiles ( $\mathrm{r}=0.992, \mathrm{r}=0.981$, respectively) in $\mathrm{OW}$ emulsions were found. Weaker correlations 272 among parameters analyzed were found in WO emulsions (Table 4). Faster hydoperoxide 273 decomposition compared to hydroperoxide formation in the WO emulsions, which leads to a reduction 274 in PV but an increase in total volatiles, contributes to the weaker correlation between PV and total 275 volatiles in this emulsion system.

276 In the secondary oxidation stage, volatile compounds (e.g. alcohols and aldehydes) are formed by the 277 decomposition of lipid hydroperoxides. In particular, volatile aldehydes have a great importance as an 278 indicator of oxidation due to their considerable contribution to the aroma and flavor deterioration of 279 the final products. The concentration of volatile compounds identified in OW and WO emulsions at 21 280 and 42 days of oxidation is summarized in Table 5. The profile of volatiles was dominated by 281 oxidation products derived from linoleic acid. As confirmed by GC-MS analysis, hexanal, (E)-2282 heptenal, $(E)$-2-octenal and $(E, E)$-2,4-decadienal were the major volatile products in the autoxidation, 283 while pentanal, 1-octen-3-ol, nonanal and $(E)$-dec-2-enal were also present in significant amounts. 284 Hexanal, $(E)$-2-octenal, 2-heptenal, pentanal,and $(E, E)$-2,4-decadienal are major oxidation products of 285 linoleic acid (Selke, Rohwedder \& Dutton, 1980; Frankel, 1998; Aidos, Jacobsen, Jensen, Luten, Van 286 der Padt \& Boom, 2002; Jiménez-Álvarez, Giuffrida, Golay, Cotting, Destaillats, Dionisi et al, 2008), 287 whereas nonanal, octanal, 1-heptanol, 1-octanol, and (E)-dec-2-enal are formed from triacylglycerols 288 containing oleic acid (Selke et al, 1980). 
The combination of caffeic acid and BSA was most effective at reducing the formation of both

290 hexanal and total volatiles in both emulsion systems. Caffeic acid was very effective at reducing 291 hexanal and total volatile formation in the OW emulsion, but its effect was weaker in the WO 292 emulsion where it was no better than BSA in reducing total volatile formation up to 35 days. This is 293 consistent with the increased hydroperoxide decomposition observed in the WO emulsion containing 294 caffeic acid (Figure 1b). The relative concentrations of the volatiles changed to some extent during the oxidation with E-2-octenal becoming a major volatile product at later stages of oxidation in the OW emulsion.

297 The antioxidant power and other important biological properties of caffeic acid are well substantiated 298 (Gülçin, 2006; Yanishlieva \& Marinova, 1995; Chen \& Ho, 1997). Caffeic acid retarded the formation of hydroperoxides in menhaden oil-in-water emulsions (Maqsood \& Benjakul, 2010), and De Leonardis \& Macciola (De Leonardis \& Macciola, 2003) reported that the antioxidant effectiveness of 301 caffeic acid was better than that of BHA in hydrophobic phases such as cod liver oil.

302 The interactions between polyphenols and albumin have attracted much attention due to their 303 importance in food (He, Liang, Wang \& Luo, , 2010; Prigent, Voragen, Visser, Van Koningsveld \& 304 Gruppen, 2007). Caffeic acid is known to bind to BSA during storage in air with antioxidant activity 305 being incorporated in the protein fraction (Bartolomé, Estrella \& Hernández, 2000; Almajano \& 306 Gordon, 2004; Almajano, Carbo, Delgado \& Gordon, 2007) but this does not occur in samples stored 307 under nitrogen (unpublished data). Confocal microscopy showed that BSA was present at the interface 308 between the oil and water phases in both an oil-in-water emulsion (Figure 3a, b), and a water-in-oil 309 emulsion (c, d). BSA can be seen clearly since it enhances the nile blue fluorescence at $670 \mathrm{~nm}$ (Lee, 310 Suh \& Li, 2003). Hence, it can be deduced that caffeic acid is oxidized to a quinone, and binds to BSA 311 by reaction with amine groups in the side chains of amino acids such as lysine, as described by Rawel, 312 Rohn, Kruse \& Kroll (2002). This transfers the caffeic acid from homogeneous solution in the aqueous 313 phase to the interface where it is more effective as an antioxidant. The caffeic acid retains a free 314 phenolic group, which is activated by a positively charged nitrogen atom as shown in scheme 1. 
317 Development of headspace volatiles by lipid oxidation was significantly affected by emulsion type.

318 The oil-in-water emulsions had a higher headspace volatile concentration, despite the degree of total 319 oxidation assessed by the TOTOX value being similar to that of the water-in-oil emulsions. Although 320 BSA had a slight antioxidant effect, it was found that BSA exerted a synergistic effect with caffeic 321 acid in both emulsion types, and this is consistent with previous reports of synergy accompanied by 322 formation of a protein-antioxidant adduct during storage (Almajano \& Gordon, 2004). BSA caused a 323 greater synergistic increase in the antioxidant activity of caffeic acid in a water-in-oil emulsion than in 324 an oil-in-water emulsion.

\section{ACKNOWLEDGMENTS}

327 EC thanks the Spanish Ministry of Education (AP2007-02164) for funding. We thank Andrew Dodson 328 and Stephen Pountney for technical assistance.

\section{REFERENCES}

330 Aidos, I.; Jacobsen, C., Jensen, B., Luten, J. B., Van der Padt, A., \& Boom, R. M. (2002). Volatile 331 oxidation products formed in crude herring oil under accelerated oxidative conditions. Eur. Food Res. 332 Technol., 104, 808-818.

333 Almajano, M. P., Carbo, R., Delgado, M. E., \& Gordon, M. H. (2007). Effect of pH on the 334 antimicrobial activity and oxidative stability of oil-in-water emulsions containing caffeic acid. J. Food 335 Sci., 72, 258-263.

336 Almajano, M. P., \& Gordon, M. H. (2004). Synergistic effect of BSA on antioxidant activities in model 337

338 AOCS Official Method cd 18-90. (1989). In Official methods and recommended practices of the 339 American Oil Chemists' Society, 4th Ed., Firestone, D. Ed., American Oil Chemists' Society: 340 Champaign, IL.

341 Arcan, I. \& Yemenicioğlu, A. (2007). Antioxidant activity of protein extracts from heat-treated or 342 thermally processed chickpeas and white beans. Food Chem., 103, 301-312.

343 Bartolomé, B., Estrella, I., \& Hernández, M. T. (2000). Interaction of low molecular weight phenolics 344 with proteins (BSA). J. Food Sci., 65, 617-621. 
Chen, J. H., \& Ho, C. T. (1997). Antioxidant activities of caffeic acid and its related hydroxycinnamic acid compounds. J. Agric. Food Chem., 45, 2374-2378.

Decker, E. A., Warner, K., Richards, M. P., \& Shahidi, F. (2005). Measuring antioxidant effectiveness in food. J. Agric. Food Chem. 53, 4303-4310.

De Leonardis A., \& Macciola V. (2003). Effectiveness of caffeic acid as an anti-oxidant for cod liver oil. Int. J. Food Sci. Technol., 38, 475-480.

Díaz, M., Dunn, C., McClements, D. J., \& Decker, E. A. (2003). Use of caseinophosphopeptides as natural antioxidants in oil-in-water emulsions. J. Agric. Food Chem., 51, 2365-2370.

Frankel, E. N. (1998). Lipid Oxidation. The Oily Press Ltd.: West Ferry, Dundee, Scotland.

Frankel, E. N., Huang, S.-W., Kanner, J., \& German, J. B. (1994). Interfacial phenomena in the evaluation of antioxidants: bulk oils vs emulsions. J. Agric. Food Chem., 42, 1054-1059.

Gülçin, I. (2006). Antioxidant activity of caffeic acid (3,4-dihydroxycinnamic acid). Toxicol., 217, 213-220.

Halliwell, B., Murcia, M. A., Chirico, S., \& Aruoma, O. I. (1995). Free radicals and antioxidants in food and in vivo: what they do and how they work. Crit. Rev. Food Sci. Nutr. 35, 7-20.

He, T., Liang, Q., Wang, Y., \& Luo, G. (2010). Characterization of the interactions between natural flavonoid compounds and bovine serum albumin by capillary electrophoresis and fluorescence method. J. Liq. Chromatogr. Rel. Technol., 33, 548-562.

Huang, S.-W., Hopia A., Schwarz K., Frankel E. N., \& German J. B. (1996). Antioxidant activity of a tocopherol and trolox in different lipid substrates: bulk oils vs oil-in-water emulsions. J. Agric. Food Chem., 44, 444-452.

Jacobsen, C., Let, M. B., Nielsen, N. S., \& Meyer, A. S. (2008). Antioxidant strategies for preventing oxidative flavour deterioration of foods enriched with n-3 polyunsaturated lipids: a comparative evaluation. Trends in Food Sci. \& Technol., 19, 76-93

Jiménez-Álvarez, D., Giuffrida, F., Golay, P. A., Cotting, C., Destaillats, F., Dionisi, F., et al.; (2008). Profiles of volatile compounds in milk containing fish oil analyzed by HS-SPMEGC/ MS. Eur. J. Lipid Sci. Technol., 110, 277-283.

Lee, S.H., Suh, J.K., \& Li, M. (2003). Determination of bovine serum albumin by its enhancement effect of nile blue fluorescence. B. Kor. Chem.Soc., 24 (1), 45-48.

Leonardis, A. D., \& Macciola, V. (2003). Effectiveness of caffeic acid as an antioxidant for cod liver oil. Int. J. Food Sci. Technol., 38, 475-480.

List, G. R., Evans, C. D., Kwolek, W. F., Warner, K., Boundy, B. K., \& Cowan, J. C. (1974). Oxidation and quality of soybean oil: A preliminary study of the anisidine test. J. Am. Oil Chem. Soc., $51,17-21$.

Mancuso, J. R., McClements, D. J., \& Decker, E. A. (1999). The effects of surfactant type, pH, and chelators on the oxidation of salmon oil-in- water emulsions. J. Agric. Food Chem. 47, 4112-4116.

Maqsood, S., \& Benjakul, S. (2010). Comparative studies of four different phenolic compounds on in vitro antioxidative activity and the preventive effect on lipid oxidation of fish oil emulsion and fish mince. Food Chem., 119, 123-132.

McClements, D. J., \& Decker, E. A. (2000). Lipid oxidation in oil-in-water emulsions: impact of molecular environment on chemical reactions in heterogeneous food systems. J. Food Sci. 65, 12701282.

Oda Y. M., Kinoshita, K., Nakayama, K., \& Kakehi, K. (1998). Evaluation of fluorescence polarization method for binding study in carbohydrate-lectin interaction. Bio. Pharm. Bulletin., 21, 1215-1217. 
389 Porter, W. L. (1993). Paradoxical behavior of antioxidants in food and biological systems. Toxicol. Ind. 390 Health., 9, 93-122.

391 Prigent, S. V. E., Voragen, A. G. J., Visser, A. J. W. G., Van Koningsveld, G. A., \& Gruppen, H. 392 (2007). Covalent interactions between proteins and oxidation products of caffeoylquinic acid 393 (chlorogenic acid). J. Sci. Food Agric., 87, 2502-2510.

394 Rampon, V., Lethuaut, L., Mouhous-Riou, N., \& Genot, C. (2001). Interface characterization and 395 aging of bovine serum albumin stabilized oil-in-water emulsions as revealed by front-surface 396 fluorescence, J. Agric. Food Chem., 49, 4046-4051.

397 Rawel, H.M., Rohn, S., Kruse, H.P., \& Kroll, J. (2002). Structural changes induced in bovine serum 398 albumin by covalent attachment of chlorogenic acid. Food Chem., 78 (4), 443-445.

399 Rouseff, R. L., \& Cadwallader, K. R. (2001). Headspace volatile aldehydes as indicators of lipid 400 oxidation in food. In Headspace techniques in foods and flavours; Kluwer Academic/Plenum 401 Publishers: New York.

402 Selke, E., Rohwedder, W. K., \& Dutton, H. J. (1980). Volatile components from trilinolein heated in 403 air, J. Am. Oil Chem. Soc., 57, 25-30.

404 Shehata, A. J., de Man. J. M., \& Alexander, J. C. (1970). A simple and rapid method for the 405 preparation of methyl esters of fats in milligram amounts for gas chromatography. Can. Inst. Food Sci. 406 Technol. J., 3, 85-89.

407 SØrensen, A. M., Haahr, A., Becker, E. M., Skibsted, L. H., Bergenståhl, B., Nilsson, L.et al. (2008). 408 Interactions between iron, phenolic compounds, emulsifiers, and $\mathrm{pH}$ in omega-3-enriched oil-in-water 409 emulsions. J. Agric. Food Chem. 56, 1740-1750.

410 Wang, W.Q., \& Goodman, M. T. (1999). Antioxidant property of dietary phenolic agents in a human 411 LDL oxidation ex vivo model: Interaction of protein binding activity, Nutr. Res., 19, 191-202.

412 Yanishlieva, N., \& Marinova, E. M. (1995). Effects of antioxidants on the stability of triacylglycerols 413 and methyl esters of fatty acids of sunflower oil. Food Chem., 54, 377-382.

414 Yoshida, H. (1993). Influence of fatty acids of different unsaturation in the oxidation of purified 415 vegetable-oils during microwave irradiation. J. Sci. Food Agric., 62, 41-47. 
Table 1. Fatty acid composition of sunflower oil

\begin{tabular}{|c|c|c|}
\hline Fatty acid name & & Amount (\%) \\
\hline Saturated (S) & & 10.42 \\
\hline Myristic acid & $\mathrm{C} 14: 0$ & $0.11 \pm 0.02$ \\
\hline Palmitic acid & $\mathrm{C} 16: 0$ & $5.72 \pm 0.04$ \\
\hline Margaric acid & C17:0 & $0.05 \pm 0.00$ \\
\hline Stearic acid & C18:0 & $3.49 \pm 0.05$ \\
\hline Arachidic acid & $\mathrm{C} 20: 0$ & $0.24 \pm 0.00$ \\
\hline Behenic acid & $\mathrm{C} 22: 0$ & $0.57 \pm 0.01$ \\
\hline Tricosanoic acid & C23:0 & $0.05 \pm 0.00$ \\
\hline Lignoceric acid & C24:0 & $0.19 \pm 0.01$ \\
\hline Unsaturated $(U)$ & & 89.58 \\
\hline Monounsaturated & & 25.25 \\
\hline Palmitoleic acid & $\mathrm{C} 16: 1$ & $0.10 \pm 0.00$ \\
\hline Oleic acid & $\mathrm{C} 18: 1(n-9)$ & $25.01 \pm 0.63$ \\
\hline Eicosenoic acid & $\mathrm{C} 20: 1(\mathrm{n}-9)$ & $0.14 \pm 0.00$ \\
\hline Polyunsaturated & & 64.33 \\
\hline Linoleic acid & $C 18: 2(n-6)$ & $64.17 \pm 0.73$ \\
\hline Linolenic acid & $C 18: 3(n-3)$ & $0.16 \pm 0.00$ \\
\hline$S: U$ & & 0.12 \\
\hline Omega 6 & & 64.17 \\
\hline Omega 3 & & 0.16 \\
\hline Omega $6:$ Omega 3 & & 401.06 \\
\hline
\end{tabular}


Table 2. Times in days for oil-in-water and water-in-oil emulsions to reach indicated values at $50{ }^{\circ} \mathrm{C}$

\begin{tabular}{|c|c|c|c|c|c|}
\hline $\begin{array}{l}\text { Oil-in-water } \\
\text { emulsion (value } \\
\text { at assessment } \\
\text { time) }\end{array}$ & $\begin{array}{l}\mathrm{PV} \\
\text { (1.79 mM } \\
\text { hydroperoxide) }\end{array}$ & $\begin{array}{l}\text { PA } \\
(0.15)\end{array}$ & $\begin{array}{l}\text { TOTOX } \\
(3.7)\end{array}$ & $\begin{array}{l}\text { Hexanal } \\
(14.63 \mu \mathrm{g} \\
\text { bromobenzene / g } \\
\text { oil) }\end{array}$ & $\begin{array}{l}\text { Total volatiles } \\
\text { ( } 585.37 \mu \mathrm{g} \\
\text { bromobenzene / g } \\
\text { oil) }\end{array}$ \\
\hline OW & 9.95 & 2.65 & 8.19 & 2.36 & 7.54 \\
\hline OW-BSA & 11.22 & 8.84 & 10.72 & 6.12 & 10.99 \\
\hline OW-CAF & 24.91 & 9.41 & 23.7 & 22.49 & 13.22 \\
\hline OW-CAF-BSA & 42.00 & 42.00 & 42.00 & 42.00 & 42.00 \\
\hline$\%$ Synergy & 97.47 & 202.60 & 102.9 & 65.95 & 277.34 \\
\hline $\begin{array}{l}\text { Water-in-oil } \\
\text { emulsion (value } \\
\text { at assessment } \\
\text { time) }\end{array}$ & $\begin{array}{l}\text { PV } \\
\text { (2.15 mM } \\
\text { hydroperoxide) }\end{array}$ & $\begin{array}{l}\text { PA } \\
(4.59)\end{array}$ & $\begin{array}{l}\text { TOTOX } \\
(9.5)\end{array}$ & $\begin{array}{l}\text { Hexanal } \\
(18.71 \mu \mathrm{g} \\
\text { bromobenzene / g } \\
\text { oil) }\end{array}$ & $\begin{array}{l}\text { Total volatiles } \\
\text { ( } 364.56 \mu \mathrm{g} \\
\text { bromobenzene / g } \\
\text { oil) }\end{array}$ \\
\hline WO & 12.87 & 17.34 & 16.2 & 3.95 & 13.42 \\
\hline WO-BSA & 15.82 & 17.26 & 17.7 & 13.77 & 15.84 \\
\hline WO-CAF & 24.47 & 39.47 & 27.2 & 17.70 & 16.02 \\
\hline WO-CAF-BSA & 42.00 & 42.0 & 35 & 42.00 & 42.00 \\
\hline \% Synergy & 100.20 & 12.10 & 50.4 & 61.49 & 468.53 \\
\hline
\end{tabular}


441 Table 3. PV, PA, TOTOX and relative concentration of total volatiles for emulsions at 42 days

\begin{tabular}{|c|c|c|c|c|c|}
\hline & $\begin{array}{l}\text { PV } \\
\text { (mM } \\
\text { hydroperoxide) }\end{array}$ & PA & TOTOX & $\begin{array}{l}\text { Total volatiles } \\
\text { ( } \mu \mathrm{g} \text { bromobenzene } \\
/ \mathrm{g} \text { oil) }\end{array}$ & $\begin{array}{l}\text { Total volatiles: } \\
\text { PA ratio }\end{array}$ \\
\hline OW & $10.43 \pm 1.97$ & $17.29 \pm 1.68$ & 38.15 & $6219.58 \pm 999.53$ & 359.72 \\
\hline OW-BSA & $7.72 \pm 1.76$ & $11.77 \pm 1.94$ & 27.21 & $5477.40 \pm 675.16$ & 465.37 \\
\hline OW-CAF & $4.82 \pm 0.03$ & $0.71 \pm 0.12$ & 10.35 & $791.53 \pm 48.42$ & 1114.83 \\
\hline OW-CAF-BSA & $1.79 \pm 0.32$ & $0.15 \pm 0.04$ & 3.73 & $585.40 \pm 48.15$ & 3902.67 \\
\hline WO & $3.97 \pm 0.33$ & $34.03 \pm 0.65$ & 41.97 & $1822.68 \pm 279.83$ & 53.56 \\
\hline WO-BSA & $2.87 \pm 0.60$ & $23.49 \pm 2.11$ & 29.23 & $1379.19 \pm 8.32$ & 58.71 \\
\hline WO-CAF & $3.42 \pm 0.34$ & $5.11 \pm 0.08$ & 11.95 & $847.29 \pm 95.04$ & 165.81 \\
\hline WO-CAF-BSA & $2.15 \pm 0.24$ & $4.59 \pm 0.91$ & 8.89 & $364.56 \pm 14.21$ & 79.42 \\
\hline
\end{tabular}


457 Table 4. Significant Pearson's correlations among parameters analyzed (PV, PA, hexanal and total 458 volatiles)

\begin{tabular}{|c|c|c|c|c|c|c|c|c|}
\hline \multirow[b]{2}{*}{$\begin{array}{l}\text { Pearson's } \\
\text { correlation: }\end{array}$} & \multicolumn{4}{|c|}{ Oil-in-water emulsion } & \multicolumn{4}{|c|}{ Water-in-oil emulsion } \\
\hline & PV & PA & Hexanal & $\begin{array}{c}\text { Total } \\
\text { volatiles }\end{array}$ & PV & PA & Hexanal & $\begin{array}{c}\text { Total } \\
\text { volatiles }\end{array}$ \\
\hline PV & - & 0.856 & 0.860 & 0.892 & - & 0.504 & 0.712 & 0.796 \\
\hline $\mathrm{PA}$ & 0.856 & - & 0.992 & 0.981 & 0.504 & - & 0.904 & 0.885 \\
\hline Hexanal & 0.860 & 0.992 & - & 0.987 & 0.712 & 0.904 & - & 0.922 \\
\hline Total volatiles & 0.892 & 0.981 & 0.987 & - & 0.796 & 0.885 & 0.922 & - \\
\hline
\end{tabular}


476 Table 5. Concentration (expressed as equivalent to bromobenzene) of volatile compounds identified in

477 oil-in-water and water-in-oil emulsions during storage at $50{ }^{\circ} \mathrm{C}$

\begin{tabular}{|c|c|c|c|c|}
\hline \multirow[t]{2}{*}{ Compound } & \multicolumn{4}{|c|}{ Concentration ( $\mu \mathrm{g}$ bromobenzene / g oil) } \\
\hline & OW (21 days) & OW (42 days) & WO (21 days) & WO (42 days) \\
\hline Butanal & 20.97 & 46.74 & 6.36 & 24.05 \\
\hline Pentanal & 15.19 & 71.97 & 14.69 & 45.71 \\
\hline (E)-2-Pentenal & 18.39 & 141.37 & nd & nd \\
\hline 1-Pentanol & 5.91 & 88.85 & 3.37 & 28.61 \\
\hline Hexanal & 70.66 & 606.9 & 61.7 & 310.26 \\
\hline 2-Hexenal & nd & 20.44 & 0.83 & 5.43 \\
\hline 2-Heptanone & nd & 10.95 & 1.25 & 7.38 \\
\hline Heptanal & nd & 60.42 & 1.75 & 14.36 \\
\hline (E)-2-Heptenal & 17.54 & 259.35 & 12.96 & 53.07 \\
\hline 1-Heptanol & 2.12 & 11.12 & 1.72 & 3.61 \\
\hline 1-Octen-3-ol & 5.93 & 117.9 & 3.64 & 15.92 \\
\hline 2-Pentyl-furan & nd & nd & 9.13 & 34.28 \\
\hline Octanal & 8.36 & 65.37 & 2.18 & 16.81 \\
\hline 3-Octen-2-one & 2.35 & 28.01 & 1.53 & 14.08 \\
\hline $\begin{array}{l}\text { 5-Ethyldihydro-2(3H)- } \\
\text { furanone }\end{array}$ & nd & nd & 13.39 & 116.33 \\
\hline (E)-2-Octenal & 15.08 & 550.12 & 2.89 & 28.28 \\
\hline 1-Octanol & 1.54 & 14.92 & 1.37 & 4.04 \\
\hline Heptanoic acid & 2.99 & 10.37 & 0.87 & 7.23 \\
\hline 2-Nonanone & 5.18 & 43.57 & 4.07 & 20.49 \\
\hline Nonanal & 10.84 & 26.5 & 3.93 & 13.61 \\
\hline$(E, E)$-2,4-Octadienal & 0.07 & 5.81 & nd & nd \\
\hline 3-Nonen-2-one & 0.55 & 15.27 & 0.47 & 2.27 \\
\hline (E)-2-Nonenal & 1.69 & 18.45 & 2.48 & 13.36 \\
\hline 2-Decanone & 0.91 & 13.77 & 1.07 & 2.67 \\
\hline$(E, E)-2,4-N o n a d i e n a l$ & 3.02 & 67.91 & 3.1 & 15.89 \\
\hline 3-Methylbut-2-enal & 11.63 & 85.71 & 3.02 & 9.98 \\
\hline Methyl-cyclodecane & 1.28 & 7.55 & 0.55 & 2.07 \\
\hline (E)-2-Decenal & 7.11 & 70.53 & 3.71 & 14.04 \\
\hline Nonanoic acid & 1.35 & 32.75 & 1.11 & 7.45 \\
\hline (E,E)-2,4-Decadienal & 70.46 & 443.56 & 19.32 & 60.09 \\
\hline 5-pentyl-5(H)-furan-2-one & 6.25 & 229.94 & 3.79 & 40.06 \\
\hline (E)-2-Tridecenal & 7.18 & 75.28 & 3.48 & 11.95 \\
\hline 6-Dodecanone & 1.16 & 34.52 & 1.06 & 3.1 \\
\hline 2-Butyloct-2-enal & 8.14 & 100.88 & 2.51 & 7.71 \\
\hline Total volatiles & 323.85 & 3376.8 & 193.3 & 954.19 \\
\hline
\end{tabular}




\section{FIGURE LEGENDS}

484 Figure 1. Changes in peroxide value and $p$-anisidine value of a) OW emulsions and b) WO emulsions 485 containing antioxidants during storage at $50{ }^{\circ} \mathrm{C}$.

486 Figure 2. Changes in hexanal and total volatiles concentration of a) OW emulsions and b) WO 487 emulsions containing antioxidants during storage at $50{ }^{\circ} \mathrm{C}$, with concentration expressed as area 488 equivalent to bromobenzene.

489 Figure 3. Oil-in-water emulsions stained with oil red- nile blue mixture (a) with BSA; (b) no protein 
A) Oil-in-water emulsion
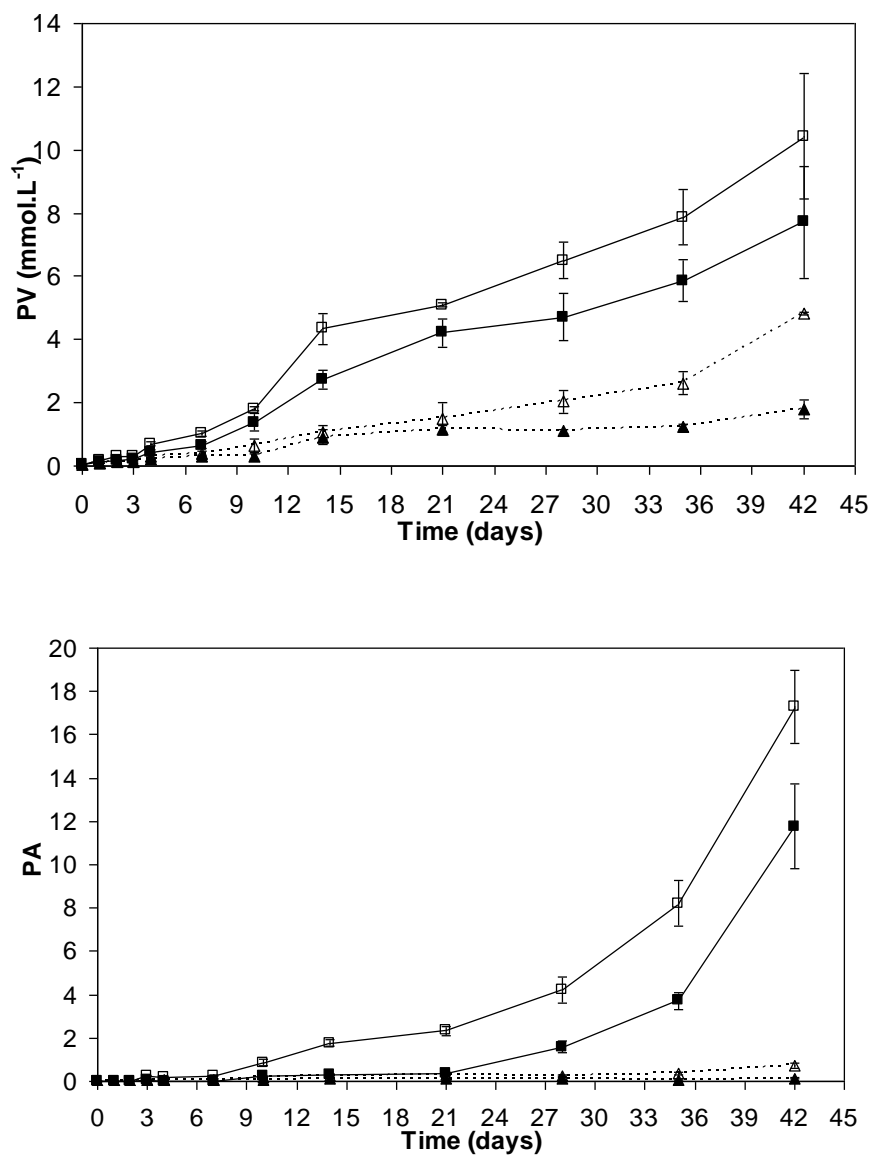
containing antioxidants during storage at $50{ }^{\circ} \mathrm{C}$

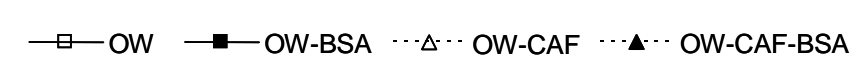

B) Water-in-oil emulsion
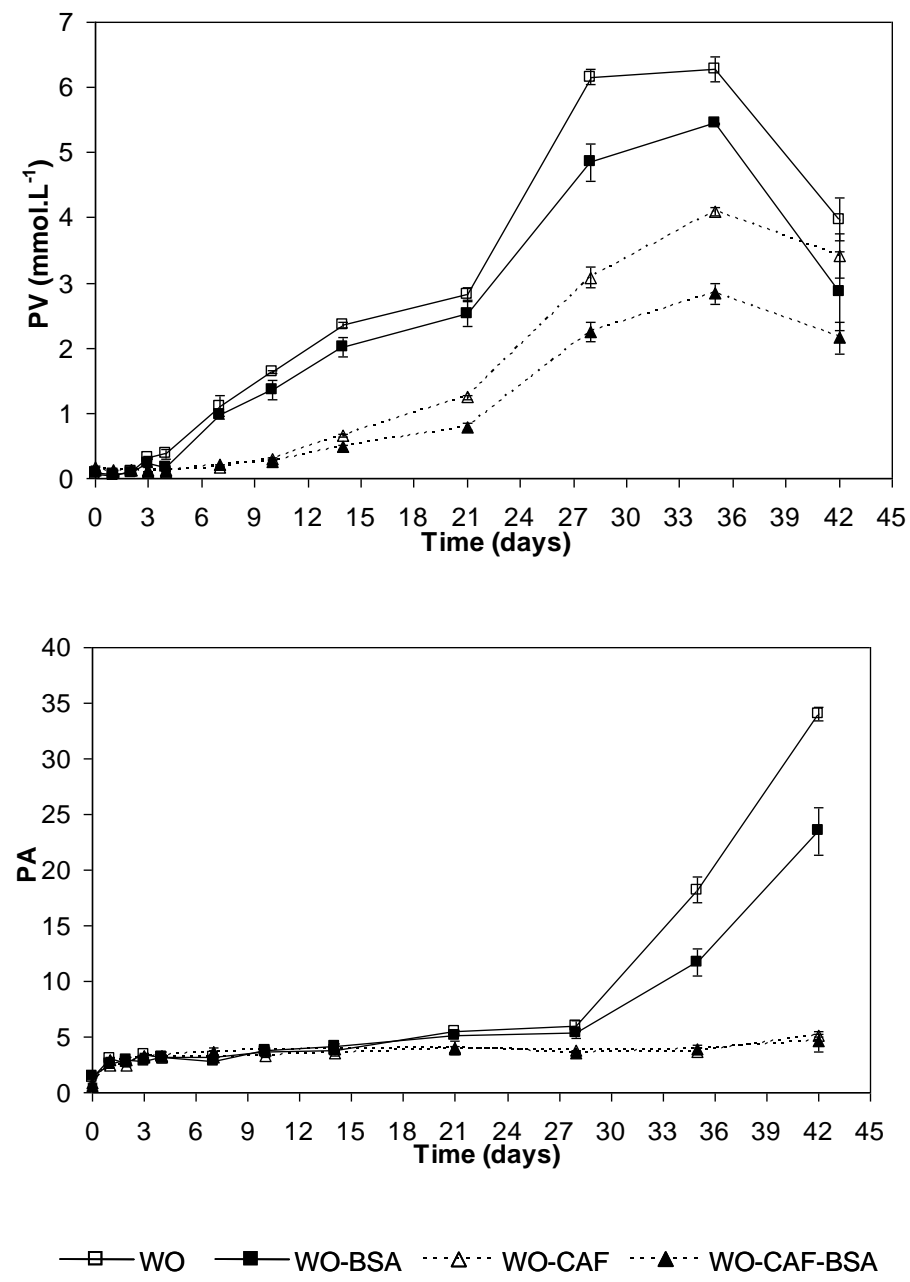
A) Oil-in-water emulsion
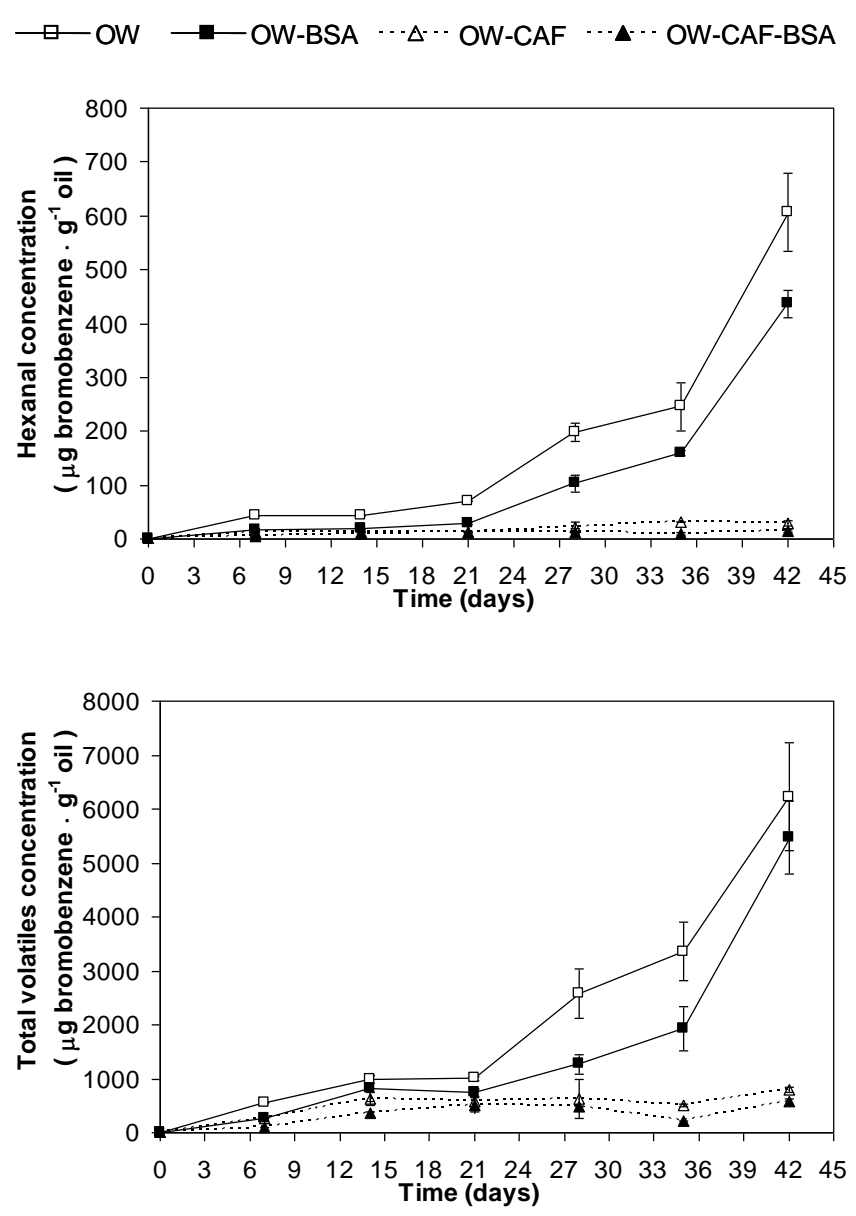

B) Water-in-oil emulsion
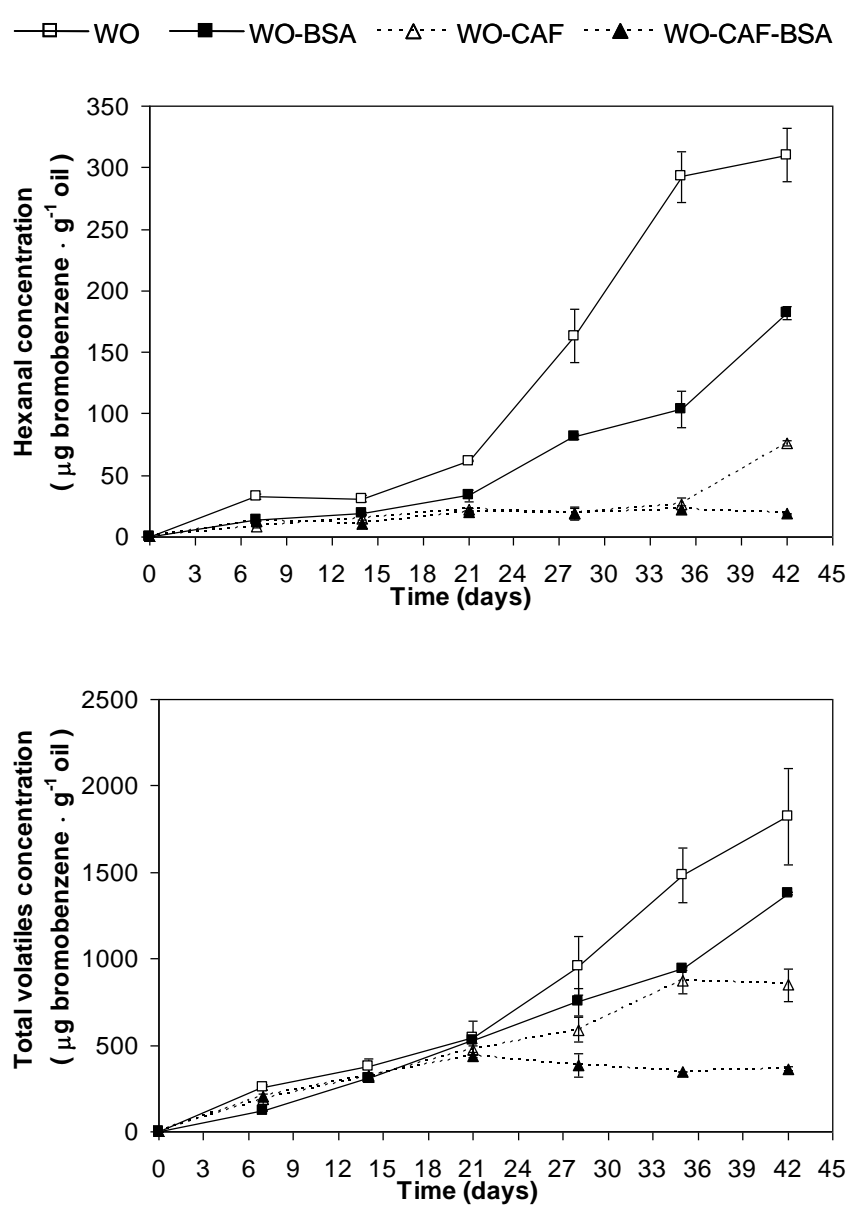

519 Figure 2. Changes in hexanal and total volatiles concentration of a) OW emulsions and b) WO

520 emulsions containing antioxidants during storage at $50{ }^{\circ} \mathrm{C}$, with concentration expressed as area 521 equivalent to bromobenzene. 


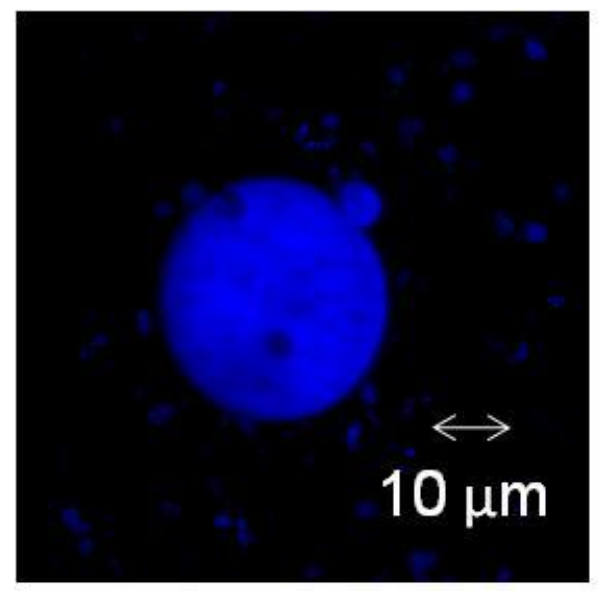

(a)

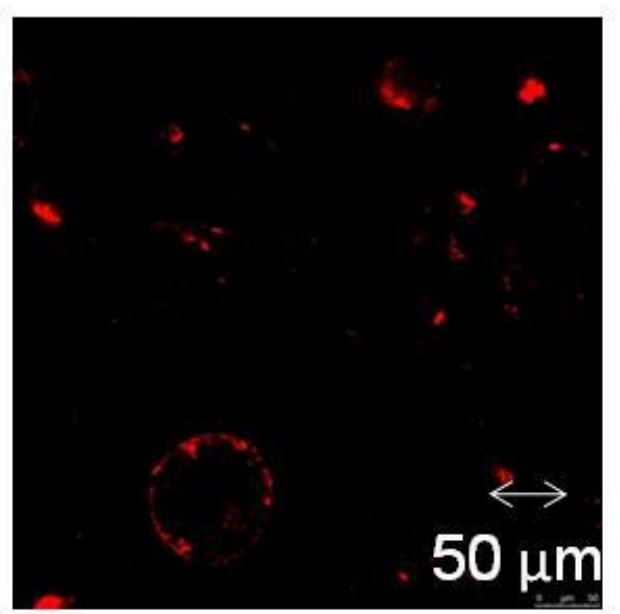

(C)

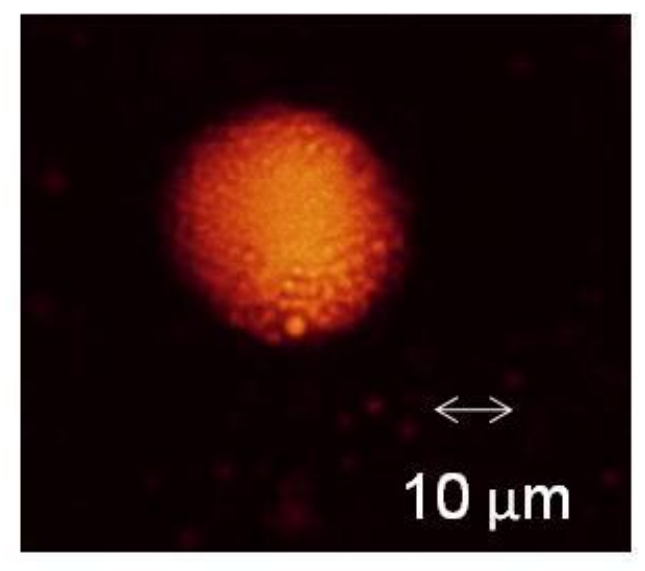

(b)

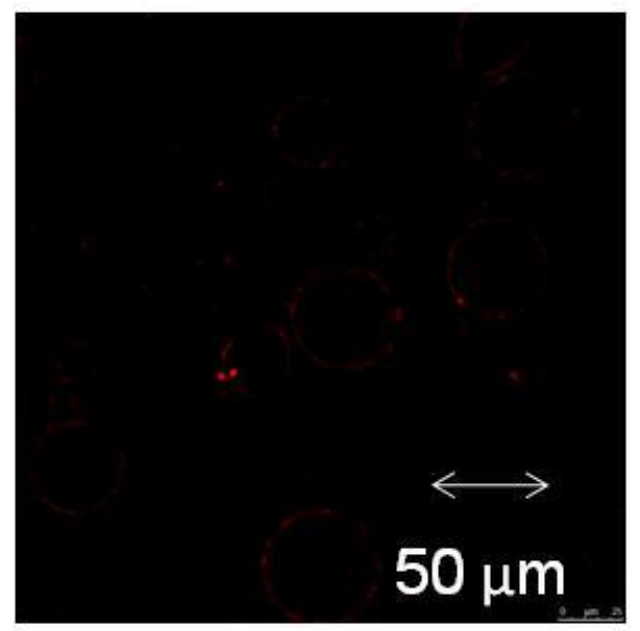

(d)

526 Figure 3. Emulsions stained with oil red- nile blue mixture (a) Oil-in-water emulsion with BSA; (b)

527 Oil-in-water emulsion with no protein; (c) water-in-oil emulsion with BSA; (d) water-in-oil emulsion

528 with no protein 

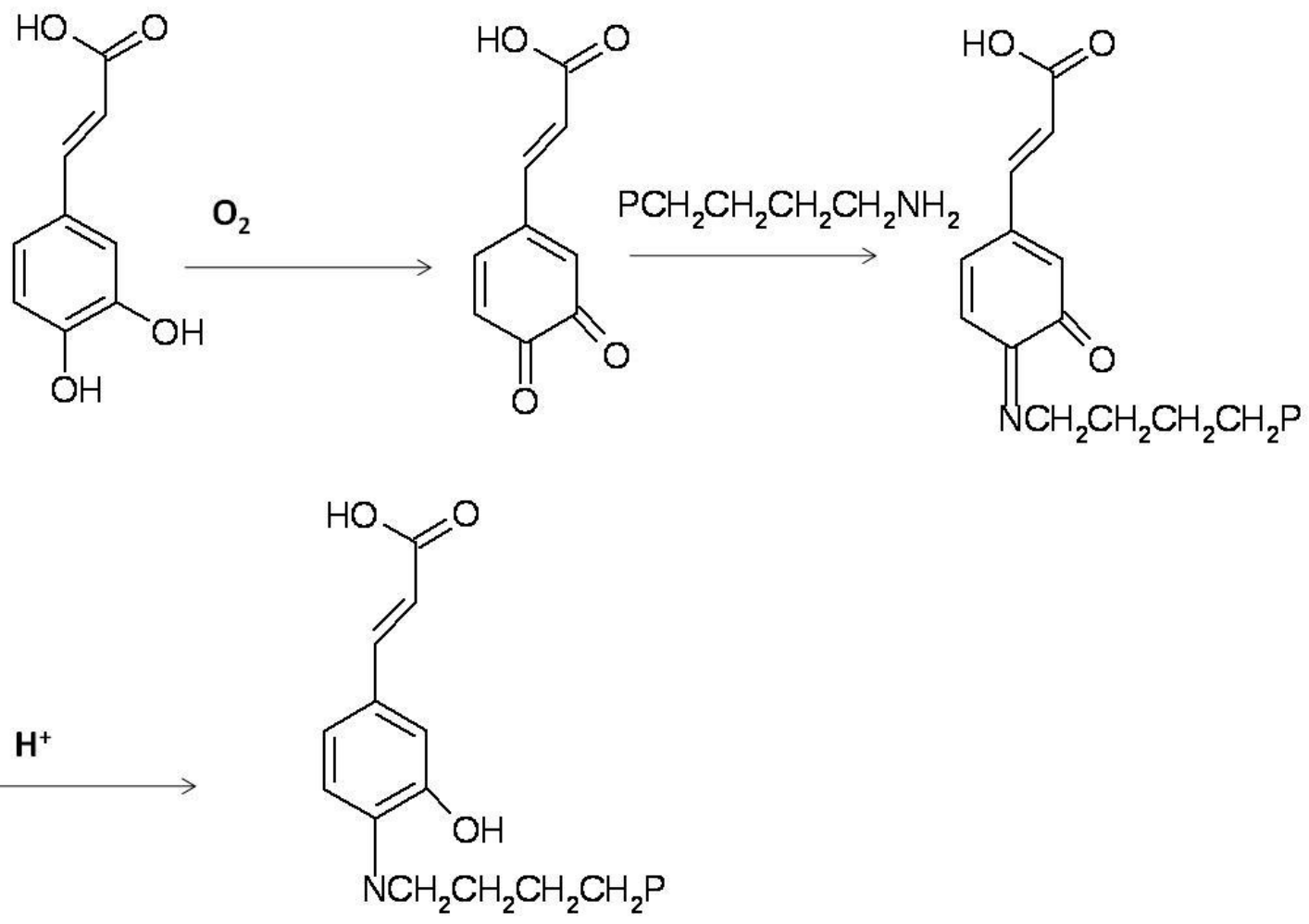

$+$

534 Scheme 1. Reaction of caffeic acid with lysine residue of BSA ( $\mathrm{P}=$ protein backbone) 